\title{
ANOLIET/CP-95041
}

\section{DEVELOPMENT OF Ag-CLAD Bi-2223 SUPERCONDUCTORS \\ FOR ELECTRIC POWER APPLICATIONS*}

\author{
U. Balachandran \\ Energy Technology Division \\ Argonne National Laboratory \\ Argonne, IL 60439 \\ V. Selvamanickam and P. Haldar \\ Intermagnetics General Corporation \\ Latham, NY 12110 \\ M. Lelovic and N. G. Eror \\ Department of Materials Science \\ University of Pittsburgh \\ Pittsburgh, PA 15261 \\ January 1998 \\ RECEIVED \\ JUL 261999 \\ OSTI

\begin{abstract}
The submitted manuscript has been created by the University of Chicago as Operator of Argonne National Laboratory ("Argonne") under Contract No. W-31-109-ENG-38 with the U.S. Department of Energy. The U.S. Government retains for itself, and others acting on its behalf, a paid-up, nonexclusive, irrevocable worldwide license in said article to reproduce, prepare derivative works, distribute copies to the public, and perform publicly and display publicly, by or on behalf of the Government.
\end{abstract}

Invited paper to be published in Proc. of Symp. of Processing and Critical Current of HTS, Wagga Wagga, Australia, Feb. 2-4, 1998.

*Work is supported by the U.S. Department of Energy, Energy Efficiency and Renewable Energy, as part of a program to develop electric power technology, under Contract W-31-109-Eng-38. 


\section{DISCLAIMER}

This report was prepared as an account of work sponsored by an agency of the United States Government. Neither the United States Government nor any agency thereof, nor any of their employees, make any warranty, express or implied, or assumes any legal liability or responsibility for the accuracy, completeness, or usefulness of any information, apparatus, product, or process disclosed, or represents that its use would not infringe privately owned rights. Reference herein to any specific commercial product, process, or service by trade name, trademark, manufacturer, or otherwise does not necessarily constitute or imply its endorsement, recommendation, or favoring by the United States Government or any agency thereof. The views and opinions of authors expressed herein do not necessarily state or reflect those of the United States Government or any agency thereof. 


\section{DISCLAIMER}

Portions of this document may be illegible in electronic image products. Images are produced from the best available original document. 
DEVELOPMENT OF Ag-CLAD Bi-2223 SUPERCONDUCTORS

FOR ELECTRIC POWER APPLICATIONS

\author{
U. Balachandran \\ Energy Technology Division \\ Argonne National Laboratory \\ Argonne, IL 60439 \\ V. Selvamanickam and P. Haldar \\ Intermagnetics General Corporation \\ Latham, NY 12110 \\ M. Lelovic and N. G. Eror \\ Department of Materials Science \\ University of Pittsburgh \\ Pittsburgh, PA 15261
}

\begin{abstract}
Development of high-temperature superconductor technology will make possible the design and fabrication of smaller, lighter, and more efficient power devices such as motors, generators, transformers, transmission cables, and fault-current limiters. A prototype fault-current limiter, a 200$\mathrm{hp}$ motor, and a 50-m-long transmission cable have already been demonstrated using Ag-clad Bi-2223 superconductor tapes. We have recently enhanced the transport current properties of long lengths of multifilament Ag-clad Bi-2223 tapes through increased packing density of precursor powder, improved mechanical deformation, optimization of conductor design, and adjusted cooling rate. These improved processing parameters had a pronounced effect on the transport critical current of the superconducting tapes. Our improvements are briefly discussed and their implications are assessed in this paper.
\end{abstract}




\section{INTRODUCTION}

As a preliminary step toward realizing the numerous potential applications of high-temperature superconductors (HTSs), a significant effort is underway to develop long-length wires and tapes with these materials. The powder-in-tube (PIT) process for the Ag-clad Bi-2223 system is a promising and industrially scaleable technique for fabricating long-length superconductors. Although considerable progress has been made recently in fabricating PIT tapes and enhancing their critical-current density $\left(\mathrm{J}_{c}\right)$ values, the complexities involved in obtaining phase purity, crystal orientation, good intergranular connectivity, and sufficient mechanical strength in a brittle multicomponent oxide have long impeded the successful commercialization of high- $T_{c}$ superconductors [1-9].

Ag-clad $\mathrm{Bi}-2223$ tapes have been incorporated into prototype HTS motors, transmission cables, and fault-current limiters; performance has generally been acceptable. However, their applicability in large electrical equipment is presently limited to the temperature range of $<30 \mathrm{~K}$ because of their low overall $J_{c}$ and susceptibility to magnetic fields. Substantial effort is now focused on addressing this limitation. Several research groups have reported that in Ag-clad Bi-2223 tapes, the supercurrent is transported through a thin region at the silver/superconductor interface [4-7,10-14]. The high-current superconducting layers are generally $\approx 2-3 \mu \mathrm{m}$ thick and have been shown to support a transport current with a $J_{c}>10^{5} \mathrm{~A} / \mathrm{cm}^{2}$ at $77 \mathrm{~K}$ and zero applied field $[4,15]$. Transport $J_{c}$ values of tapes with identical superconductor cross-sectional areas but differing $\mathrm{Ag} / \mathrm{Bi}-2223$ interfacial lengths confirm the importance of the interfacial region [11]. The critical current was shown to be proportional to the Ag/Bi-2223 
interface perimeter length (IPL), expressed as a linear function. These results imply that $<10 \%$ of the $\mathrm{Bi}-2223$ superconductor transports the vast majority of supercurrent in Ag-clad Bi-2223 tapes. Thus, $J_{C}$ values can be increased by microstructural design through optimization of the IPL.

Efforts to enhance $J_{c}$ by increasing the $\mathrm{Ag} / \mathrm{Bi}-2223$ interfacial area continue. Fabrication of multifilamentary tapes achieves this goal, but in general the areal fraction of $\mathrm{Ag}$ increases for such tapes [16]. An alternative approach is to incorporate $\mathrm{Ag}$ wires into a $\mathrm{Bi}-2223$ core. Initial work focused on use of a single Ag wire [4,17,18]. In addition to offering possibilities for improved transport $\mathrm{J}_{\mathrm{c}}$, significant enhancement of bendstrain tolerance with a wire-in-tube approach has been reported [18].

This duplex-core work has recently been extended to a two-step process in which many fine Ag wires are coated with Bi-2223 precursor powder and then loaded into an Ag tube. Conventional PIT working then produces a tape with a very high $\mathrm{Ag} / \mathrm{Bi}-2223$ interfacial area $[14,19]$. To date, up to $600 \mathrm{Ag}$ wires, coated with Bi-2223 precursor, have been loaded into a single Ag tube and processed into tapes. Despite the smaller cross-sectional area of the superconducting core, transport $\mathrm{J}_{\mathrm{c}}$ values are now greater than those of corresponding monofilament tapes [14].

Parrel et al. [8] observed that the cooling rate from the sintering temperature had a significant effect on $J_{c}$ and attributed the effect to partial decomposition of Bi-2223 during slow cooling. However, other changes in the Bi-2223 also arise from slow cooling, e.g., increase in oxygen content [20]. In previous work with the University of Pittsburgh [21], we also showed that cooling rate had a pronounced effect on $J_{c}$. The thin layer of 
$\mathrm{Bi}-2223$ adjacent to the Ag sheath was placed under compression during fast cooling; the compressive stress induced microcracking and hence a lower $\mathrm{J}_{\mathrm{c}}$. A slow-cooling rate minimized the cracking.

Significant effort is being expended to improve $\mathrm{J}_{\mathrm{C}}$ in $\mathrm{Bi}-2223$ conductors by tailoring powder conditions, morphologies, and packing, mechanical processing, and heat treatment [9,22]. Recently, we have varied the packing density of the precursor powder, improved the mechanical processing, and modified the heat treating schedule; the results are described in this paper.

\section{EXPERIMENTAL PROCEDURE AND RESULTS}

Multifilament Ag-clad Bi-2223 tapes were made by the PIT technique with precursor powders having the overall stoichiometry of Bi-2223. The precursor powder contained $\mathrm{Pb}$-added 2212, $\mathrm{Ca}_{2} \mathrm{PbO}_{4}$, alkaline-earth cuprate, and $\mathrm{CuO}$ phases. Packing density in the Ag tubes was varied by using precursor powder, including that prepressed into billets, that was inserted into the $\mathrm{Ag}$ tubes. The precursor powder was packed into the $\mathrm{Ag}$ tubes at a density of $\approx 2.3 \mathrm{~g} / \mathrm{cm}^{3}$, while the precursor billets were of two densities: $\approx 3.5 \mathrm{~g} / \mathrm{cm}^{3}$ (low packing-density) and $\approx 4.5 \mathrm{~g} / \mathrm{cm}^{3}$ (high packing density). The powder and prepressed billet Ag tubes were swaged, drawn through a series of dies, and then rolled to a final thickness of $\approx 200 \mu \mathrm{m}$. Standard mechanical processing consisting of $>10 \%$ reduction per pass was used in the fabrication of these tapes. Samples measuring $\approx 1.5 \mathrm{~m}$ in length were cut from these three tapes and heat treated in $8 \%$ oxygen atmosphere. The transport critical current, $I_{C}(77 \mathrm{~K}$, self-field, $1 \mu \mathrm{v} / \mathrm{cm}$ criterion), measured in tapes that were heat treated at $810-825^{\circ} \mathrm{C}$ are shown in Fig. 1. 
The higher packing density resulted in higher $I_{C}$ values when heat treated at $820^{\circ} \mathrm{C}$. These higher $\mathrm{I}_{\mathrm{C}}$ values were maintained uniformly over a length of $\approx 1.5 \mathrm{~m}$ (see Fig. 2). The ratio between $\mathrm{Ag}$ and superconductor core crosssectional area in the tape depends on precursor packing density. Higher initial packing density might lead to increased superconductor crosssectional area and thereby increased $\mathrm{I}_{\mathrm{C}}$.

In another set of experiments, we varied the mechanical deformation schedule. The Ag tubes packed with the precursor powder and prepressed billets were drawn and rolled according to various reduction ratios per pass. Load cells were mounted on the dies, and pressure exerted on the wires being drawn was monitored. Onset of mechanical stability during wire drawing was recorded by monitoring the pressure exerted on the wires. Reduction ratios per pass were optimized on the basis of the die pressure measurements. The cross-sectional area of each sample was observed by scanning electron microscopy (SEM). Figure 3 is a composite of lowmagnification SEM images showing the effect of mechanical deformation on the cross sections of two multifilament tapes. Improved mechanical processing of the high-density precursor billet Ag tube showed a pronounced effect on the uniformity of the $\mathrm{Ag} /$ superconductor interface. The standard mechanical processing consisted of $>10 \%$ reduction per pass, while the improved mechanical processing reduced the rate of mechanical deformation to $<10 \%$ reduction per pass. The $I_{c}$ values of tape processed with improved mechanical deformation conditions were uniform $(\approx 36$ A) for a 5-m-long tape. 
In a parallel experiment, we studied the effect of cooling rates on the $I_{C}$ of tapes. Approximately 1 -m-long tapes were heated to $\approx 800^{\circ} \mathrm{C}$ at a rate of $\approx 2^{\circ} \mathrm{C} / \mathrm{min}$, held for $50 \mathrm{~h}$, and then cooled. The standard cooling rate was $1-2^{\circ} \mathrm{C} / \mathrm{min}$, but slower rates were also used. All heat treatments were conducted in $8 \%$ oxygen atmosphere. Figure 4 shows the effect of cooling rate on $I_{C}$ values of tapes $1.2 \mathrm{~m}$ long. Slow cooling $\left(\approx 10^{\circ} \mathrm{C} / \mathrm{h}\right)$ in the temperature range $820-790^{\circ} \mathrm{C}$ improved the $I_{c}$ over that achieved with the standard cooling rate. The thermal gradient between the Ag sheath and the $\mathrm{Bi}-2223$ core exerted a compressive stress on the thin layer of Bi-2223 adjacent to the Ag; this stress affected grain alignment and connectivity. In extreme cases, compression caused by a strong thermal gradient induced microcracking in the Bi-2223. Singh and Vasanthamohan [23] studied the cooling-rate effect of $\mathrm{Bi}-2223$ samples sintered at 815 and $825^{\circ} \mathrm{C}$ in $8 \% \mathrm{O}_{2}$ atmosphere and noticed that when the cooling rate was decreased from $100^{\circ} \mathrm{C} / \mathrm{h}$ to $10^{\circ} \mathrm{C} / \mathrm{h}$, tapes sintered at $815^{\circ} \mathrm{C}$ showed very little change in $\mathrm{J}_{\mathrm{c}}$ whereas tapes sintered at $825^{\circ} \mathrm{C}$ showed an increased $J_{c}$. This difference was attributed to how the Bi-2223 phase is formed at the two temperatures. For the tapes sintered at $825^{\circ} \mathrm{C}$, they [23] noticed an increase in $\mathrm{Bi}-2223$ phase content with a decrease in cooling rate; hence, $J_{c}$ increases with a decrease in cooling rate. Incorporation of these improvements in packing density of powders, mechanical deformation, and cooling rate has now resulted in consistent $I_{c}$ values for long lengths $(>100 \mathrm{~m})$ of superconducting tapes.

Poor mechanical properties have seriously hampered the commercial application of high- $T_{c}$ superconductors. During fabrication and service, the conductors are subjected to axial and bending stresses. In operation, the 
material is subjected to additional stresses by temperature gradients and magnetic fields. In large and/or high-field magnets, electromagnetic hoop stresses could even reach the ultimate strength of the material. These stresses can cause microstructural damage in the conductors and thereby degrade current transport properties. Although silver is widely used as a sheath material, its mechanical properties are not adequate to withstand the stresses developed during fabrication and service. Therefore, techniques such as adding silver to the superconductor powder, using alloy sheath material as an alternative to silver, and fabricating multifilament conductors have been developed to improve the strain tolerance characteristics of the conductors $[24,25]$.

When carrying an alternating current or in the presence of a changing magnetic field, HTSs exhibit energy losses that generate heat, which, in turn, could lead to degradation of the current-carrying properties of the tapes. The level of such losses will have a critical impact on the commercial potential and engineering feasibility of an application. Twisting the tapes and employing an alloy sheath material will mitigate the AC-loss characteristics of conductors [26].

\section{CONCLUSIONS}

Transport current properties in multifilament Ag-clad Bi-2223 superconducting tapes were improved by varying the mechanical and thermal parameters during tape processing. The packing density of precursor powder, improved mechanical deformation, and cooling rate all had a pronounced effect on the critical current of the superconducting 
tapes. Good transport of supercurrent seems to be confined to core regions adjacent to the Ag sheath.

\section{ACKNOWLEDGMENT}

The work is supported by the U.S. Department of Energy, Energy Efficiency and Renewable Energy, as part of a program to develop electric power technology, under Contract W-31-109-Eng-38.

\section{REFERENCES}

1. R. Flükiger, B. Hensel, A. Jeremie, A. Perin, and J. C. Grivel, Appl. Supercon., 1 (1993) 709 .

2. S. X. Dou and H. K. Liu, Supercond. Sci. Technol., $\underline{6}$ (1993), 297.

3. U. Balachandran, A. N. Iyer, and P. Haldar, JOM, 46 (1994) 23.

4. M. Lelovic, P. Krishnaraj, N. G. Eror, and U. Balachandran, Supercond. Sci. Technol. $\underline{8}$ (1995) 334.

5. S. P. Ashworth and B. A. Glowacki, Physica C, 226 (1994) 159.

6. H. K. Liu, R. K. Wang, and S. X. Dou, Physica C, $\underline{229}$ (1994) 39.

7. Y. Feng and D. C. Larbalestier, Interface Sci. 1 (1994) 401.

8. J. A. Parrel, D. C. Larbalestier, and S. E. Dorris, IEEE Trans. Appl. Supercond. $\underline{5}$ (1995), 1275.

9. U. Balachandran, A. N. Iyer, R. Jammy, P. Haldar, J. G. Hoehn, Jr., and M. Suenaga, Adv. Cryo. Eng. $\underline{42}$ (1997), 753. 
10. M. Lelovic, P. Krishnaraj, N. G. Eror, A. N. Iyer, and U. Balachandran, Supercond. Sci. Technol. $\underline{9}$ (1996) 201.

11. B. C. Prorok, M. Lelovic, T. A. Deis, P. Krishnaraj, N. G. Eror, A. N. Iyer, and U. Balachandran, Adv. Cryo. Eng. $\underline{42}$ (1997) 739.

12. D. C. Larbalestier, X. Y. Cai, Y. Feng, H. Edelman, A. Umezawa, G. N. Riley, Jr., and W. L. Carter, Physica C 221 (1994) 299.

13. U. Welp, D. O. Gunter, G. W. Crabtree, W. Zhong, U. Balachandran, P. Haldar, R. S. Sokolowski, V. K. Vlasko-Vlasov, and V. I. Nikitenko, Nature, $\underline{367}$ (1995) 44.

14. S. E. Dorris, N. Ashcom, T. Truchan, N. Vasanthamohan, D. A. Burlone, and L. D. Woolf, to be published in Proc. Supercond. Symp., 99th Ann. Mtg. Am. Ceram. Soc., Cincinnati, May 4-7, 1997.

15. M. Lelovic, P. Krishnaraj, N. G. Eror, and U. Balachandran, Physica C, $\underline{242}$ (1995) 246.

16. W. G. Wang, J. Horvat, H. K. Liu, and S. X. Dou, Supercond. Sci. Technol. $\underline{9}$ (1996) 875 .

17. J. Schwartz, H. Sekine, T. Asano, T. Kuroda, K. Inoue, and H. Maeda, IEEE Trans. Magn. 27 (1991) 1247.

18. N. Vasanthamohan and J. P. Singh, Supercond. Sci. Technol. 10 (1997) 113. 
19. S. E. Dorris, in Practical Superconductor Development for Electrical Power Systems, Argonne National Laboratory Report ANL-95/42 (1995) 13.

20. M. Tetenbaum and V. A. Maroni, Physica C $\underline{260}$ (1996) 71.

21. M. Lelovic, T. Deis, N. G. Eror, U. Balachandran, and P. Haldar, Supercond. Sci. Technol. $\underline{9}$ (1996) 965.

22. Z. Han and T. Freltoft, Appl. Supercond. $\underline{2}$ (1994) 201.

23. J. P. Singh and N. Vasanthamohan, J. Mater. Res. (1998, in press).

24. J. P. Singh, J. Joo, N. Vasanthamohan, and R. B. Poeppel, J. Mater. Res. $\underline{8}$ (1993) 2458.

25. J. Schwartz, J. K. Heuer, K. C. Goretta, R. B. Poeppel, J. Guo, and G. W. Raban, Jr., Appl. Supercond. $\underline{2}$ (1994) 271.

26. A. P. Malozemoff, Q. Li, S. Fleshler, G. N. Riley, Jr., G. Snitchles, and D. Aized, presented at 1995 Taiwan Intl. Conf. on Superconductivity, Hualien, Taiwan, Aug. 8-11, 1995. 


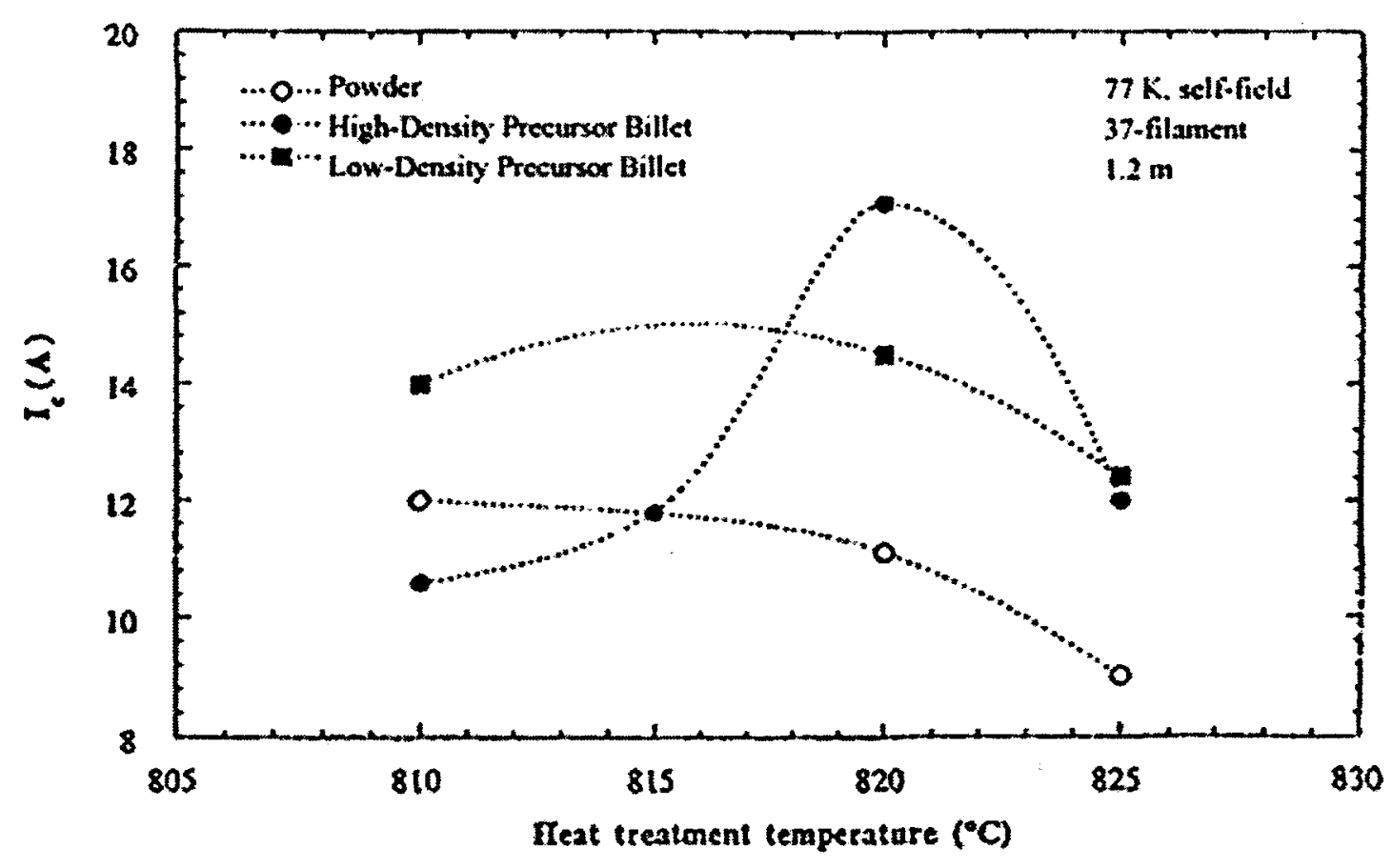

Fig. 1. Transport critical current $\left(I_{c}\right)$ as a function of heat treatment temperature for tapes with various precursor powder packing densities. 


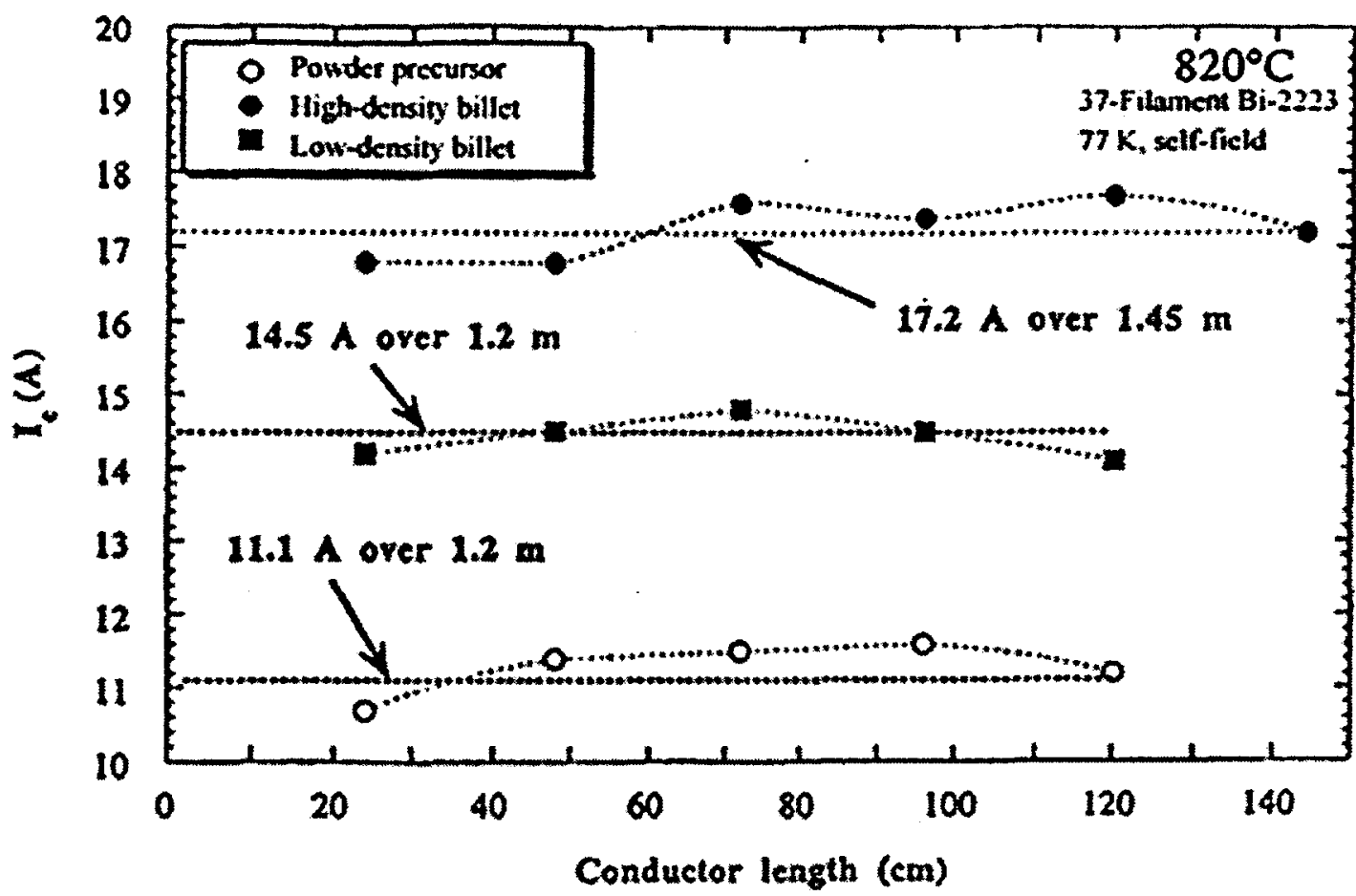

Fig. 2. Transport $I_{C}$ along lengths of tapes made with various precursor powder packing densities. 

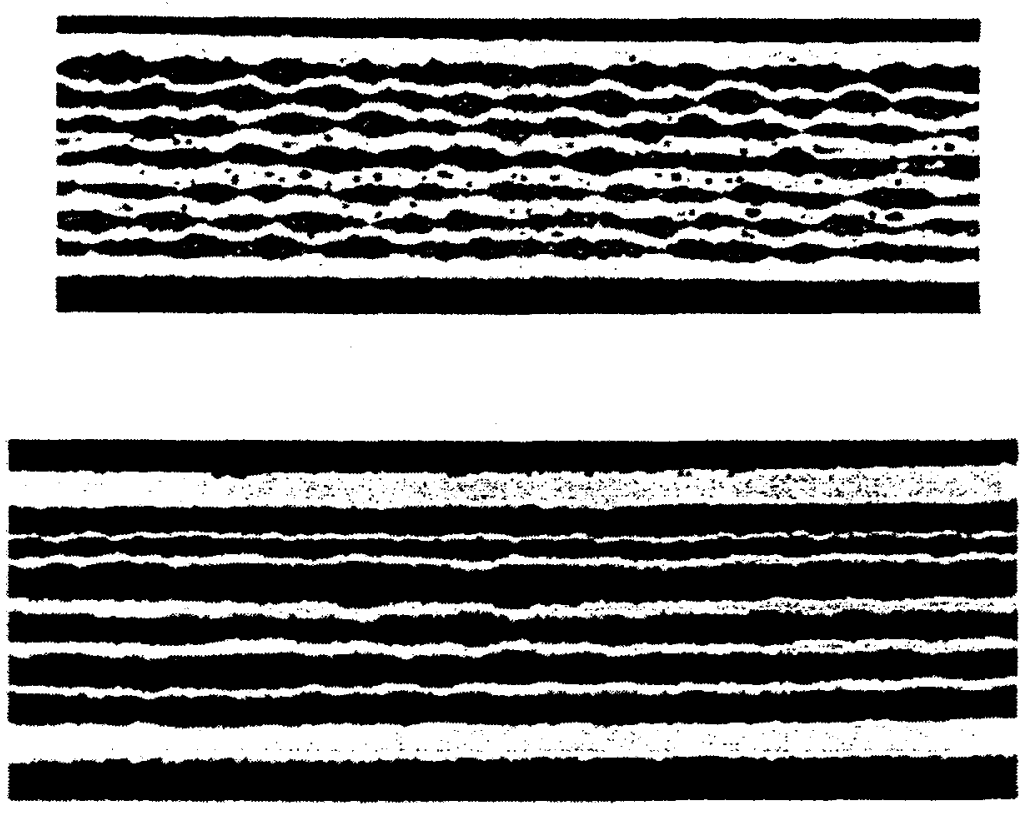

Consolidated Precursor Rod Improved Mechanical Processing $I_{c}=36 \mathrm{~A}$

Fig. 3. SEM photomicrograph of multifilament tapes showing effect of improved mechanical processing. Tapes processed under standard mechanical processing are shown for comparison. 


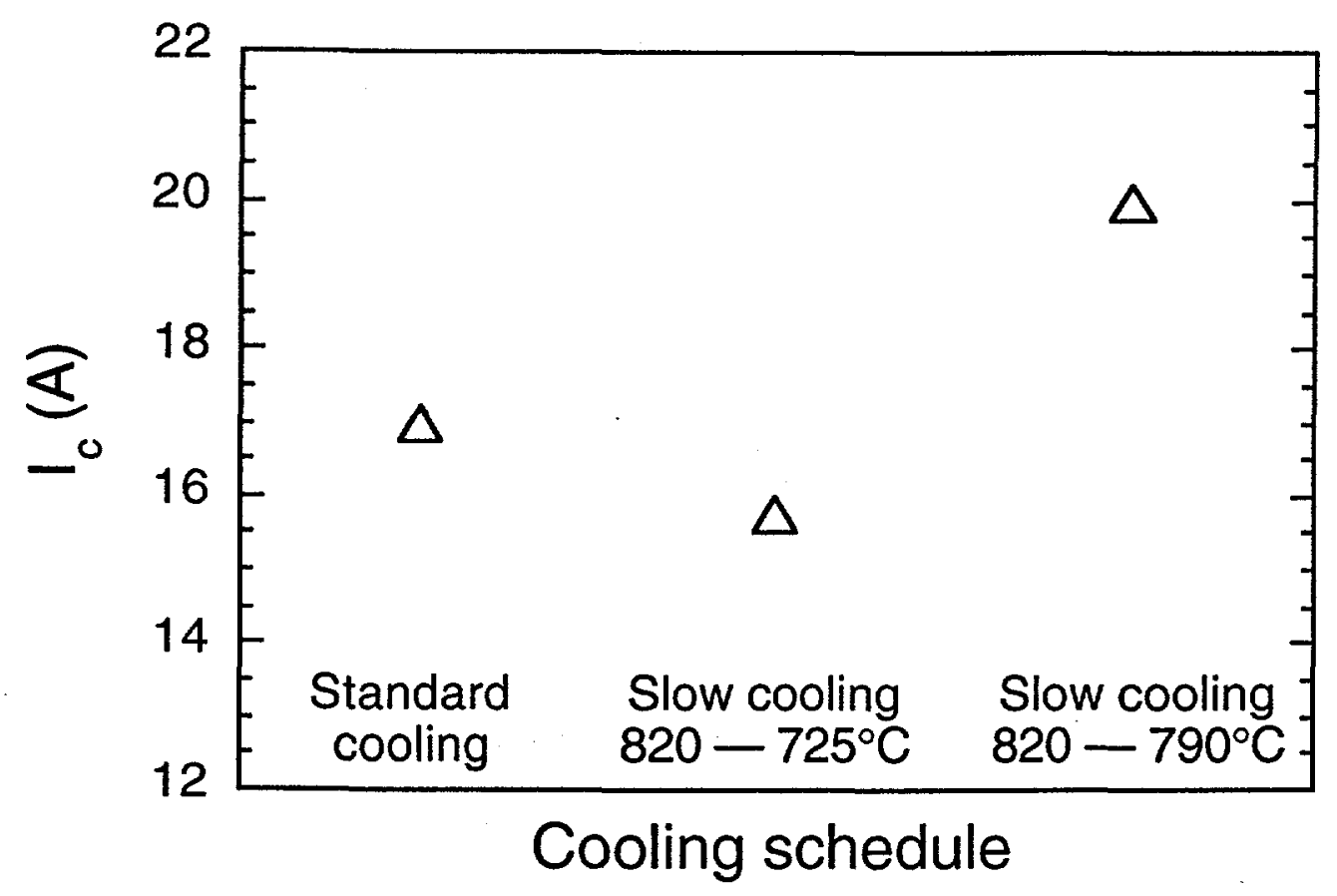

Fig. 4. Transport $\mathrm{I}_{\mathrm{c}}$ along 1.2-m-long tape vs. cooling condition. 